\title{
Stereoselective conjugate addition of organolithium reagents to unprotected 4-hydroxy-2-cyclopentenones
}

\author{
Gabriela de la Herrán, Joaquín Plumet, Amaya Segura, Araceli Silverio, \\ and Aurelio G. Csák̈̈* \\ Departamento de Química Orgánica I, Facultad de Química, Universidad Complutense, \\ 28040-Madrid, Spain \\ E-mail: csaky@quim.ucm.es
}

Dedicated to Professor Arlette Solladié-Cavallo on occasion of her 70th birthday

\begin{abstract}
The stereoselective conjugate addition reaction of organolithium reagents to unprotected 4hydroxycyclopentenones is reported. The $\mathrm{OH}$ group on the substrate is transformed into the corresponding magnesium alkoxide, which has been used to control the regioselectivity of the organolithium addition. Following this procedure, the conjugate addition reaction was obtained instead of the products of direct addition to the carbonyl group usually found in other organolithium additions to similar starting materials. Additionally, the $\mathrm{OH}$ group controls the cisstereochemistry of the final products. Both aspects, regio- and stereoselectivity, can be understood by means of a chelation-controlled addition.
\end{abstract}

Keywords: Cyclopentenones, organolithium reagents, conjugate addition

\section{Introduction}

4-Hydroxy-2-cyclopentenones and their $O$-silyl derivatives $\mathbf{1}$ constitute valuable synthetic intermediates. In particular, their regio- and stereocontrolled transformation into the 4,5disubstituted 3-hydroxycyclopentanones $\mathbf{2}$ is a cornerstone in the synthetic approach to prostaglandins and related bioactive compounds. ${ }^{1}$ Thus, additions of dialkylcuprates or Grignard reagents in the presence of copper(I) salts to compounds 1 take place in a 1,4-anti fashion with respect to the bulky $O$-silyl substituent (Scheme 1). Electrophilic capture of the intermediate enolates affords cyclopentanones 2 with a 3,4-trans-4,5-trans stereochemistry in a threecomponent coupling. Similar findings have been reported for the reaction of $O$-silyl protected $2-$ substituted 4-hydroxy-2-cyclopentenones 3 with organocopper reagents.

On the other hand, a highly regio- and stereoselective method for the conjugate addition to unprotected 2-substituted 4-hydroxy-2-cyclopentenones 4 has been reported making use of 
readily available Grignard reagents. ${ }^{2,3}$ This procedure allows to establish a 3,4-cis-4,5-trans stereochemistry, complementary to that observed in the 1,4-addition of organocuprates, and also makes possible the attachment of either alkyl or aryl groups to carbons C-4 and C-5 of cyclopentenones 5 (Scheme 1).
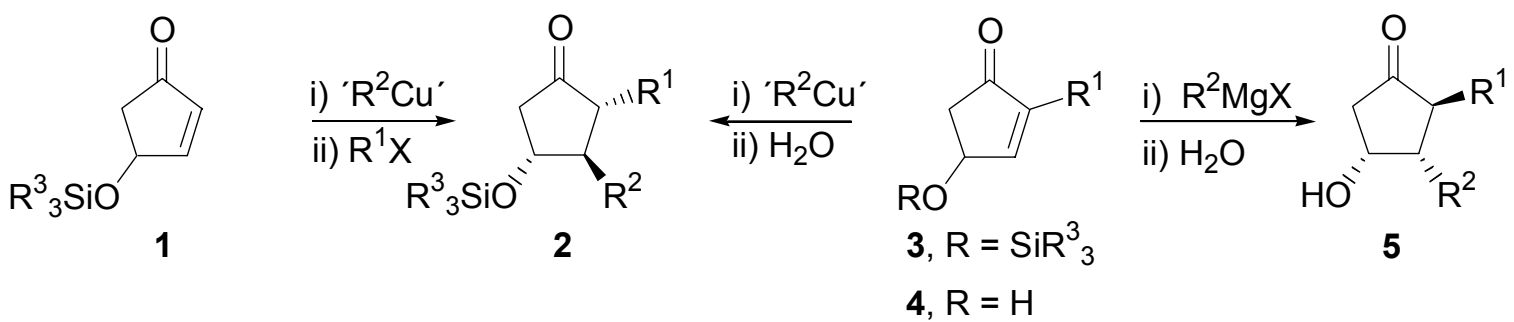

5

4, $\mathrm{R}=\mathrm{H}$

Scheme 1. Conjugate addition reactions to protected or unprotected 4-hydroxycyclopentenones.

In a similar fashion, conjugate addition of aryl and alkenyl groups to compounds $\mathbf{4}$ has been possible by using boronic acids in combination with $\mathrm{Rh}(\mathrm{I})$-catalysis. ${ }^{4}$ However, it is worth mentioning that the direct addition of alkyl or aryllithiums (2.0 equiv.) to compounds 4 gives rise to the products of direct addition to the carbonyl group 6 (1,2-addition) (Scheme 2). ${ }^{2}$
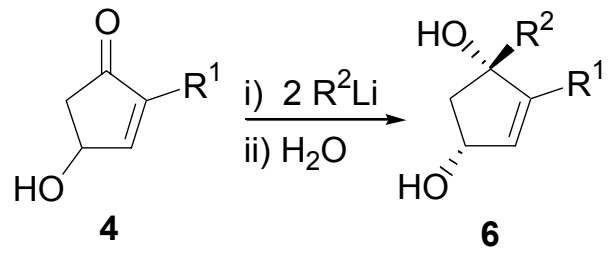

Scheme 2. Addition of organolithium compounds to unprotected 4-hydroxycyclopentenones.

In comparison with the introduction of alkyl, alkenyl and aryl groups, the conjugate addition of acetylides to unsaturated carbonyl acceptors is considerably underrepresented in the list of available methods for conjugate reactions. ${ }^{5,6}$ Contrary to their alkyl or alkenyl counterparts, copper acetylides only add to unsaturated ketones under forcing conditions, and therefore have been commonly used as dummy ligands on mixed cuprates allowing for the selective transfer of alkyl or alkenyl groups in conjugate addition reactions. We report herein the succesfull lithium acetylide and alkyllithium conjugate addition to compounds 4.

\section{Results and Discussion}

The starting 2-substituted 4-hydroxy-2-cyclopentenones 4 were prepared by ring-opening of (2furyl)carbinols as previously reported. ${ }^{7}$ Initial studies on the direct addition of lithium phenylacetylide $7 \mathbf{a}\left(2.0\right.$ equiv.) to compound $4 \mathbf{a}\left(\mathrm{R}^{1}=\mathrm{Ph}\right)$ led to a mixture of the corresponding 
1,4- and 1,2-addition products 5a and 6a in a 50:50 ratio (Scheme 3). Although discouraging from a regioselectivity standpoint, this result was relevant, as alkyl or aryllithium additions to compound $\mathbf{4 a}$ had been reported to be highly selective in favor of compounds $\mathbf{6} .^{2}$
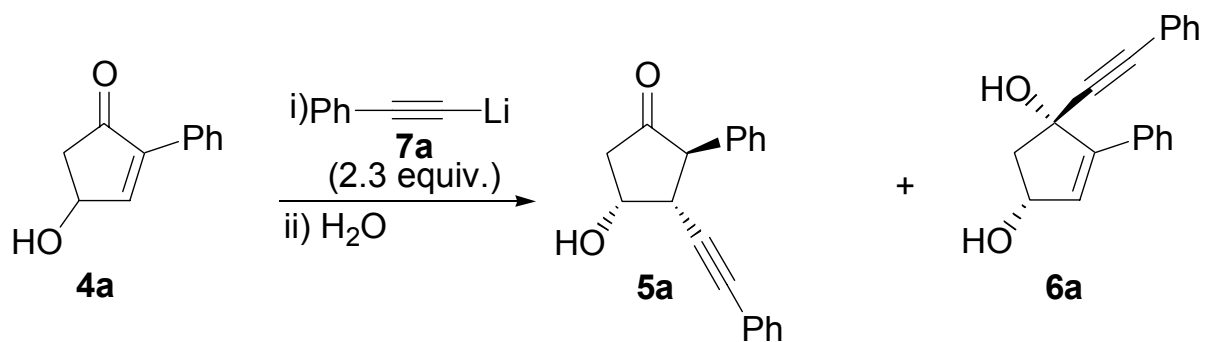

$5 \mathbf{a}: \mathbf{6 a}=50: 50(40 \%$ yield $)$

Scheme 3. Addition of lithium phenylacetylide 7a to 4-hydroxy-2-cyclopentenone 4a.

We then turned our attention to the possibility of exerting a ligand assisted nucleophilic addition $^{8}$ by deprotonating the $\mathrm{OH}$ group with an organomagnesium reagent prior to reaction with lithium acetylides. ${ }^{9,10}$ Thus, treatment of compound $4 \mathbf{a}$ with ${ }^{\mathrm{t}} \mathrm{BuMgCl}$ (1.0 equiv.) followed by reaction with $7 \mathbf{a}$ (2.3 equiv.) afforded a mixture of 5a and $6 \mathbf{a}$ in a $80: 20$ ratio (Scheme 4 and Table 1, entry 1).<smiles>[R]C1=CC(O)CC1=O</smiles>

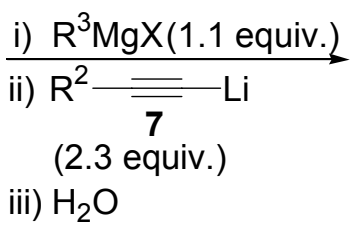
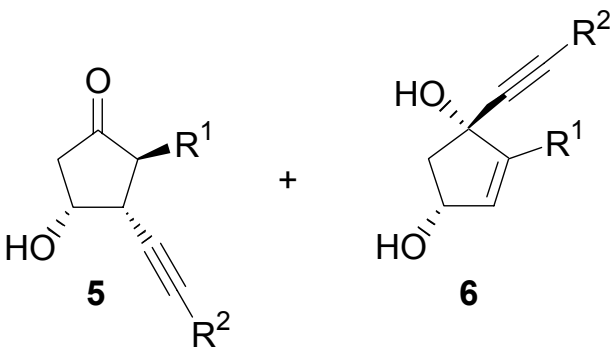

Scheme 4. Addition of lithium acetylides 7 to 4-hydroxycyclopentenones 4.

Optimization of the reaction conditions (Table 1 , entries 3 -7) led to $\mathrm{MeMgBr}$ as the best choice to carry out fast deprotonation at low temperature without competence of either 1,2- or 1,4-addition of $\mathrm{R}^{3}$ to compound $\mathbf{4 a}$. However, reaction of compound $\mathbf{4 b}$ under similar conditions gave rise to a mixture of $\mathbf{5 d}$ and $\mathbf{6 d}$ (Table 1, entry 8).

The same reaction conditions were applied to the reaction of butyllithium with cyclopentenone 4a (Scheme 5), giving rise to a mixture of 8 and 9 in $80: 20$ ratio (65\% overall yield). 
Table 1. Addition of lithium acetylides 7 to 4 -hydroxycyclopentenones $4^{\text {a }}$

\begin{tabular}{cccccc}
\hline Entry & $\mathbf{4}, \mathrm{R}^{1}$ & $\mathbf{7}, \mathrm{R}^{2}$ & $\mathrm{R}^{3} \mathrm{MgX}$ & $\mathbf{5}: \mathbf{6}$, ratio $^{\mathrm{b}}$ & Yield (\%) $^{\mathbf{c}}$ \\
\hline 1 & $\mathbf{4 a}, \mathrm{R}^{1}=\mathrm{Ph}$ & $\mathbf{7 a}, \mathrm{R}^{2}=\mathrm{Ph}$ & ${ }^{\mathrm{t}} \mathrm{BuMgCl}$ & $\mathbf{5 a}: \mathbf{6 a}=80: 20$ & 80 \\
$2^{\mathrm{d}}$ & $\mathbf{4 a}, \mathrm{R}^{1}=\mathrm{Ph}$ & $\mathbf{7 a}, \mathrm{R}^{2}=\mathrm{Ph}$ & ${ }^{\mathrm{t}} \mathrm{BuMgCl}$ & $\mathbf{5 a}: \mathbf{6 a}=80: 20$ & 30 \\
3 & $\mathbf{4 a}, \mathrm{R}^{1}=\mathrm{Ph}$ & $\mathbf{7 b}, \mathrm{R}^{2}={ }^{\mathrm{n}} \mathrm{C}_{4} \mathrm{H}_{9}$ & ${ }^{\mathrm{t}} \mathrm{BuMgCl}$ & $\mathbf{5 b}: \mathbf{6 b}=95: 05$ & 65 \\
4 & $\mathbf{4 a}, \mathrm{R}^{1}=\mathrm{Ph}$ & $\mathbf{7 a}, \mathrm{R}^{2}=\mathrm{Ph}$ & ${ }^{\mathrm{i}} \mathrm{PrMgCl}$ & $\mathbf{5 a}: \mathbf{6 a}=80: 20$ & 70 \\
5 & $\mathbf{4 a}, \mathrm{R}^{1}=\mathrm{Ph}$ & $\mathbf{7 a}, \mathrm{R}^{2}=\mathrm{Ph}$ & $\mathrm{MeMgBr}$ & $\mathbf{5 a}: \mathbf{6 a}=95: 05$ & 85 \\
6 & $\mathbf{4 a}, \mathrm{R}^{1}=\mathrm{Ph}$ & $\mathbf{7 b}, \mathrm{R}^{2}={ }^{\mathrm{n}} \mathrm{C}_{4} \mathrm{H}_{9}$ & $\mathrm{MeMgBr}$ & $\mathbf{5 b}: \mathbf{6 b}=95: 05$ & 60 \\
7 & $\mathbf{4 a}, \mathrm{R}^{1}=\mathrm{Ph}$ & $\mathbf{7 c}, \mathrm{R}^{2}=\mathrm{TMS}$ & $\mathrm{MeMgBr}$ & $\mathbf{5 c}: \mathbf{6 c}=70: 30$ & 65 \\
8 & $\mathbf{4 b}, \mathrm{R}^{1}=\mathrm{CH}_{3}$ & $\mathbf{7 a}, \mathrm{R}^{2}=\mathrm{Ph}$ & $\mathrm{MeMgBr}$ & $\mathbf{5 d}: \mathbf{6 d}=60: 40$ & 65 \\
\hline
\end{tabular}

${ }^{\text {a }}$ Reactions carried out by addition of $\mathrm{R}^{3} \mathrm{MgX}$ (1.1 equiv.) to a solution of 4 in THF, followed by addition of 7 (2.3 equiv.) unless otherwise stated. ${ }^{b}$ Determined by integration of the ${ }^{1} \mathrm{H}-\mathrm{NMR}$ spectra of the reaction crudes. ${ }^{c}$ Isolated yield. ${ }^{\mathrm{d}}$ Reaction carried out with 1.1 equiv. of $7 \mathbf{a}$.<smiles>O=C1CC(O)C=C1c1ccccc1</smiles>

$4 a$ i) $\operatorname{MeMgBr}(1.1$ equiv.)

ii) BuLi (2.3 equiv.)

iii) $\mathrm{H}_{2} \mathrm{O}$

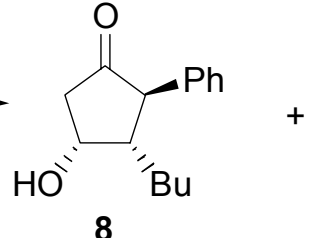

8

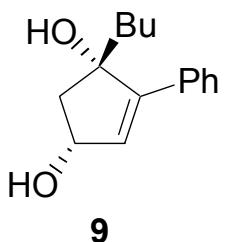

Scheme 5. Addition of butyllithium to 4-hydroxycyclopentenone 4a.

These results can be understood on the basis of a chelation-controlled addition promoted by the magnesium alkoxide I formed in situ upon deprotonation of the starting materials with the $\mathrm{R}^{3} \mathrm{MgX}$ reagents (Scheme 6). ${ }^{9}$

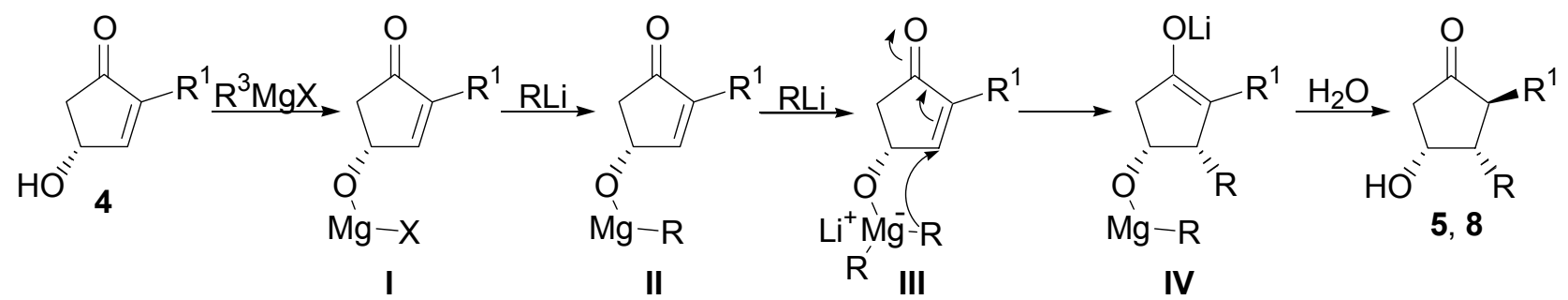

Scheme 6. Proposed reaction course for the magnesium alkoxide promoted conjugate addition of organolithiums to the unprotected 4-hydroxycyclopentenones 4.

Thus, reaction of I with one equivalent of an organolithium reagent RLi, either lithium acetylide or alkyllithium, will give rise to intermediate II, which will be transformed into a magnesate III upon addition of a second equivalent of RLi. Transfer of the organic moiety R to the $\beta$-carbon of the unsaturated ketone will take place stereoselectively (syn-addition) affording 
enolate IV. Final protonation of the alkoxide and $\alpha$-protonation of the enolate from the less hindered diastereotopic face will give rise to compounds $\mathbf{5}$ or $\mathbf{8}$.

In light of the proposed reaction course, we studied the possibility of reducing the amount of lithium acetylides 7 required for conjugate addition with the aid of a second organolithium reagent $\left({ }^{\mathrm{t}} \mathrm{BuLi}\right)^{9}$ which was presumed to transfer more slowly than the acetylide moiety (Scheme 7).
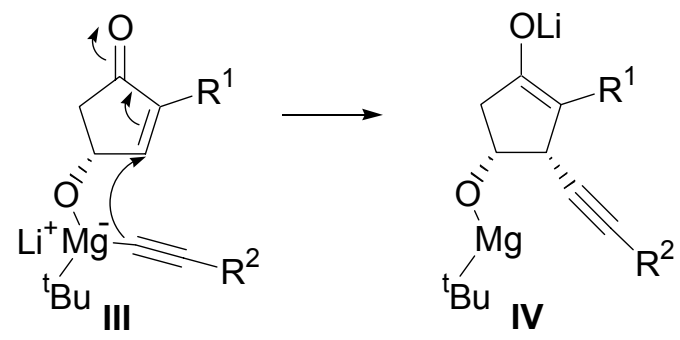

Scheme 7. Preferential transfer of the acetylide moiety from the mixed magnesate III.

We observed that treatment of compounds 4 with $\operatorname{MeMgBr}\left(1.1\right.$ equiv.) followed by ${ }^{t} \mathrm{BuLi}$ (1.0 equiv.) and 7 (1.1 equiv.) gave rise to a complex mixture of reaction products, from which the product of 1,2-addition of the ${ }^{t} \mathrm{Bu}$ group $\mathbf{1 0}$ was isolated (50\% yield). On the other hand, treatment of compounds 4 with $\mathrm{MeMgBr}$ (1.1 equiv.) followed first by 7 (1.1 equiv.) and last by ${ }^{t} \mathrm{BuLi}$ (1.0 equiv.) allowed for the isolation of the conjugate addition products $\mathbf{5}$. The results are given in Scheme 6 and Table 2.

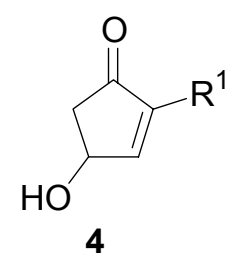

i) $\mathrm{MeMgBr}$ (1.1 equiv.)

ii) $R^{2} \frac{\overline{\overline{ }}}{7} \mathrm{Li}(1.1$ equiv.)

iii) ${ }^{\mathrm{t} B u L i}(1.0$ equiv.)
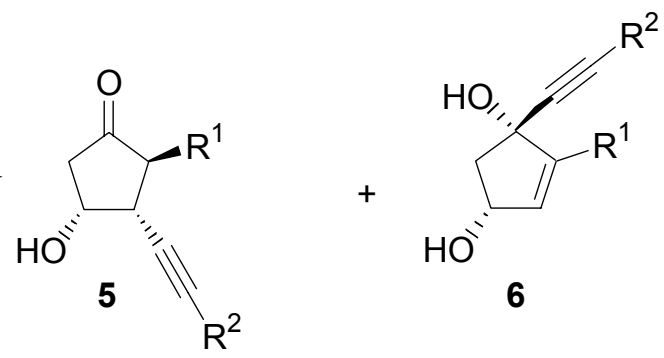

Scheme 6. ${ }^{\text {B } B u L i-p r o m o t e d ~ a d d i t i o n ~ o f ~ l i t h i u m ~ a c e t y l i d e s ~} 7$ to 4 -hydroxycyclopentenones 4. 
Table 2. Addition of lithium acetylides 7 and ${ }^{\mathrm{t}} \mathrm{BuLi}$ to 4 -hydroxycyclopentenones 4

\begin{tabular}{ccccc}
\hline Entry & $\mathbf{4}, \mathrm{R}^{1}$ & $\mathbf{7}, \mathrm{R}^{2}$ & $\mathbf{5}: \mathbf{6}$, ratio & Yield (\%) \\
\hline 1 & $\mathbf{4 a}, \mathrm{R}^{1}=\mathrm{Ph}$ & $\mathbf{7 a}, \mathrm{R}^{2}=\mathrm{Ph}$ & $\mathbf{5 a}: \mathbf{6} \mathbf{a}=95: 05$ & 80 \\
2 & $\mathbf{4 a}, \mathrm{R}^{1}=\mathrm{Ph}$ & $\mathbf{7 b}, \mathrm{R}^{2}={ }^{\mathrm{n}} \mathrm{C}_{4} \mathrm{H}_{9}$ & $\mathbf{5 b}: \mathbf{6 b}=95: 05$ & 65 \\
3 & $\mathbf{4 a}, \mathrm{R}^{1}=\mathrm{Ph}$ & $\mathbf{7 c}, \mathrm{R}^{2}=\mathrm{TMS}$ & $\mathbf{5 c}: \mathbf{6 c}=70: 30$ & 65 \\
4 & $\mathbf{4 b}, \mathrm{R}^{1}=\mathrm{CH}_{3}$ & $\mathbf{7 a}, \mathrm{R}^{2}=\mathrm{Ph}$ & $\mathbf{5 d}: \mathbf{6 d}=60: 40$ & 60 \\
\hline
\end{tabular}

${ }^{a}$ Reactions carried out by addition of $\mathrm{MeMgBr}$ (1.1 equiv.) to a solution of 4 in THF, followed by add-on of 7 (1.1 equiv.) and ${ }^{t} \mathrm{BuLi}$ (1.0 equiv.). ${ }^{b}$ Determined by integration of the ${ }^{1} \mathrm{H}-\mathrm{NMR}$ spectra of the reaction crudes. ${ }^{c}$ Isolated yield.

These results put forward that the expected conjugate addition products 5a (Table 2, entries 1-3) could be obtained with good selectivities by promoting the conjugate addition of the acetylide moiety by interaction of ${ }^{t} \mathrm{BuLi}$ with the aggregate II initially formed between the magnesium alkoxide and acetylides 7 . However, compound $\mathbf{4 b}$ did also give a mixture of $\mathbf{5 d}$ and 6d (Table 2, entry 4) under these reaction conditions (compare with Table 1, entry 8)

In conclusion, the conjugate addition of organolithium reagents to the unprotected 2-substituted 4-hydroxy-2-cyclopentenones $\mathbf{4}$ is possible by treating the corresponding magnesium alkoxide with a Grignard reagent (best choice, $\mathrm{MeMgBr}$ ) followed by either an excess of organolithium reagent (2.3 equiv.) or, in the case of lithium acetylides, by adding first 7 (1.1 equiv.) followed by ${ }^{t} \mathrm{BuLi}$ (1.0 equiv.). Best results in yield an diastereoselectivity were found for compounds $\mathbf{4}$ substituted at $\mathrm{C} 2$ with a phenyl group.

\section{Experimental Section}

General Procedures. All reactions were carried out under argon. THF was dried with Na under Ar and distilled prior to use. ${ }^{1} \mathrm{H}$ NMR $(200 \mathrm{MHz})$ and ${ }^{13} \mathrm{C}$ NMR $(50 \mathrm{MHz})$ spectra were obtained on a Bruker AC-200 using $\mathrm{CDCl}_{3}$ as solvent and TMS as internal standard. Analytical TLC was performed on Merck silica gel plates and the spots were visualised under UV light $(\lambda=254 \mathrm{~nm})$. Flash column chromatography was carried out on Merck silica gel $60(0.040-0.063 \mathrm{~mm})$. Compounds 4 were prepared from furans as previously reported. ${ }^{7}$

\section{General procedure for the conjugate addition of organolithium compounds to hydroxycyclopentenones 4 . Method A}

To a solution of $4(0.17 \mathrm{mmol})$ in THF $(0.2 \mathrm{~mL})$ at $-78^{\circ} \mathrm{C}$ was added dropwise a $3 \mathrm{M}$ solution of $\mathrm{R}^{3} \mathrm{MgBr}(0.19 \mathrm{mmol})$. The mixture was stirred 10 minutes at $-78^{\circ} \mathrm{C}$. The temperature was then allowed to rise gradually to $0^{\circ} \mathrm{C}$. After the mixture was stirred for 30 minutes, a solution of RLi $(0.39 \mathrm{mmol})$ in THF $(0.4 \mathrm{~mL})$ was added. The mixture was stirred for $18 \mathrm{~h}$ at room temperature and hydrolyzed with saturated $\mathrm{NH}_{4} \mathrm{Cl}$ solution $(0.5 \mathrm{~mL})$. The organic layer was decanted and the 
aqueous layer extracted with $\mathrm{Et}_{2} \mathrm{O}(3 \mathrm{x} 5 \mathrm{~mL})$. The combined organic layers were dried on $\mathrm{MgSO}_{4}$, filtered, and concentrated in vacuo. Purification was carried out by chromatography with hexane/ethyl acetate (1:2) as the eluent, giving rise to compounds $\mathbf{5}$ or $\mathbf{8}$.

General procedure for the conjugate addition of lithium acetylides 7 to hydroxycyclopentenones 4. Method B

To a solution of $4(0.17 \mathrm{mmol})$ in THF $(0.2 \mathrm{~mL})$ at $-78^{\circ} \mathrm{C}$ was added dropwise a $3 \mathrm{M}$ solution of $\mathrm{R}^{3} \mathrm{MgBr}(0.19 \mathrm{mmol})$. The mixture was stirred 10 minutes at $-78^{\circ} \mathrm{C}$. The temperature was then allowed to rise gradually to $0^{\circ} \mathrm{C}$. After the mixture was stirred for 30 minutes, a solution of 7 $(0.19 \mathrm{mmol})$ in THF $(0.2 \mathrm{~mL})$ was added. The mixture was stirred 30 minutes and then, a $1.5 \mathrm{M}$ solution of ${ }^{\mathrm{t}} \mathrm{BuLi}$ in pentane $(113 \mu \mathrm{L}, 0.17 \mathrm{mmol})$ was added. The mixture was stirred for $18 \mathrm{~h}$ at room temperature and hydrolyzed with saturated $\mathrm{NH}_{4} \mathrm{Cl}$ solution $(0.5 \mathrm{~mL})$. The organic layer was decanted and the aqueous layer extracted with $\mathrm{Et}_{2} \mathrm{O}(3 \times 5 \mathrm{~mL})$. The combined organic layers were dried on $\mathrm{MgSO}_{4}$, filtered, and concentrated in vacuo. Purification was carried out by chromatography with hexane/ethyl acetate $(1: 2)$ as the eluent, giving rise to compounds 5.

4-Hydroxy-2-phenyl-3-phenylethynylcyclopentanone (5a). ${ }^{1} \mathrm{H}$ NMR (200 $\left.\mathrm{MHz}, \mathrm{CDCl}_{3}\right) \delta$ 7.39 - $7.15(\mathrm{~m}, 10 \mathrm{H}), 4.61(\mathrm{~m}, 1 \mathrm{H}), 3.77(\mathrm{~d}, \mathrm{~J}=12.3 \mathrm{~Hz}, 1 \mathrm{H}), 3.36(\mathrm{dd}, \mathrm{J}=3.5 \mathrm{~Hz}, \mathrm{~J}=12.2 \mathrm{~Hz}$, $1 \mathrm{H}), 2.68(\mathrm{~d}, \mathrm{~J}=18.9 \mathrm{~Hz}, 1 \mathrm{H}), 2.51(\mathrm{dd}, \mathrm{J}=4.8 \mathrm{~Hz}, \mathrm{~J}=18.9 \mathrm{~Hz}, 1 \mathrm{H}) .{ }^{13} \mathrm{C} \mathrm{NMR}(50.5 \mathrm{MHz}$, $\left.\mathrm{CDCl}_{3}\right) \delta 214.2,136.5,131.9,128.9,128.7,128.6,128.5,127.6,126.2,87.1,85.9,68.5,57.0$, 46.1, 44.6. Anal. Calcd. for $\mathrm{C}_{19} \mathrm{H}_{16} \mathrm{O}_{2}$ : C, 82.58; H, 5.84. Found: C, 82.74; H, 5.92.

3-Hex-1-ynyl-4-hydroxy-2-phenylcyclopentanone (5b). ${ }^{1} \mathrm{H}$ NMR $\left(200 \mathrm{MHz}, \mathrm{CDCl}_{3}\right) \delta 7.26$ $7.10(\mathrm{~m}, 5 \mathrm{H}), 4.45(\mathrm{~m}, 1 \mathrm{H}), 3.59(\mathrm{~d}, \mathrm{~J}=12.1 \mathrm{~Hz}, 1 \mathrm{H}), 3.12(\mathrm{~m}, 1 \mathrm{H}), 2.63(\mathrm{~d}, \mathrm{~J}=19.0 \mathrm{~Hz}, 1 \mathrm{H})$, $2.42(\mathrm{dd}, \mathrm{J}=5.1 \mathrm{~Hz}, \mathrm{~J}=18.9 \mathrm{~Hz}, 1 \mathrm{H}), 2.14(\mathrm{~m}, 2 \mathrm{H}), 1.38(\mathrm{~m}, 4 \mathrm{H}), 0.85(\mathrm{t}, 3 \mathrm{H}, \mathrm{J}=6.9 \mathrm{~Hz}) .{ }^{13} \mathrm{C}$ NMR $\left(50.5 \mathrm{MHz}, \mathrm{CDCl}_{3}\right) \delta 214.0,130.5,129.1,128.5,127.1,88.3,87.6,68.6,60.8,46.2,44.4$, 30.1, 21.4, 18.8, 13.9. Anal. Calcd. for $\mathrm{C}_{17} \mathrm{H}_{20} \mathrm{O}_{2}$ : C, 79.65; H, 7.86. Found: C, 79.81; H, 7.98.

4-Hydroxy-2-phenyl-3-trimethylsilanylethynylcyclopentanone (5c). ${ }^{1} \mathrm{H}$ NMR (200 MHz, $\left.\mathrm{CDCl}_{3}\right) \delta 7.25-6.99(\mathrm{~m}, 5 \mathrm{H}), 4.39(\mathrm{~m}, 1 \mathrm{H}), 3.55(\mathrm{~d}, \mathrm{~J}=12.0,1 \mathrm{H}), 3.03(\mathrm{dd}, \mathrm{J}=3.5 \mathrm{~Hz}, \mathrm{~J}=12.0$ $\mathrm{Hz}, 1 \mathrm{H}), 2.55(\mathrm{~d}, \mathrm{~J}=18.6 \mathrm{~Hz}, 1 \mathrm{H}), 2.34(\mathrm{dd}, \mathrm{J}=4.8 \mathrm{~Hz}, \mathrm{~J}=19.3 \mathrm{~Hz}, 1 \mathrm{H}), 0.01(\mathrm{~s}, 9 \mathrm{H}) .{ }^{13} \mathrm{C}$ NMR $\left(50.5 \mathrm{MHz} \mathrm{CDCl}_{3}\right) \delta 202.5,135.8,128.7,128.5,127.5,89.2,87.9,67.9,56.9,45.9,45.0,0.1$. Anal. Calcd. for $\mathrm{C}_{16} \mathrm{H}_{20} \mathrm{O}_{2} \mathrm{Si}$ : C, 70.54; H, 7.40. Found: C, 70.73; H, 7.28.

3-Butyl-4-hydroxy-2-phenylcyclopentanone (8). ${ }^{1} \mathrm{H} \mathrm{NMR}\left(200 \mathrm{MHz}, \mathrm{CDCl}_{3}\right) \delta 7.32$ - 6.96 (m, $5 \mathrm{H}), 4.55(\mathrm{~d}, \mathrm{~J}=1.96 \mathrm{~Hz}, 1 \mathrm{H}), 3.26(\mathrm{~d}, \mathrm{~J}=12.5 \mathrm{~Hz}, 1 \mathrm{H}), 2.51(\mathrm{~m}, 3 \mathrm{H}), 1.74(\mathrm{~m}, 2 \mathrm{H}), 1.34(\mathrm{~m}$, $4 \mathrm{H}), 0.81(\mathrm{t}, 3 \mathrm{H}) .{ }^{13} \mathrm{C} \mathrm{NMR}\left(50.5 \mathrm{MHz}, \mathrm{CDCl}_{3}\right) \delta 213.1,132.5,128.6,127.8,126.9,67.9,57.8$, 53.3, 48.2, 30.8, 29.4, 22.7, 13.8. Anal. Calcd. for $\mathrm{C}_{15} \mathrm{H}_{20} \mathrm{O}_{2}$ : C, 77.55; H, 8.68. Found: C, 77.73; $\mathrm{H}, 8.61$.

1- ${ }^{\mathrm{t}}$ Butyl-5-phenylcyclopent-4-ene-1,3-diol (10). ${ }^{1} \mathrm{H} \mathrm{NMR}\left(200 \mathrm{MHz}, \mathrm{CDCl}_{3}\right) \delta 7.47$ - 7.15 (m, 5H), $5.87(\mathrm{~d}, \mathrm{~J}=1.96 \mathrm{~Hz}, 1 \mathrm{H}), 4.62-4.56(\mathrm{~m}, 1 \mathrm{H}), 2.93(\mathrm{dd}, \mathrm{J}=7.1 \mathrm{~Hz}, \mathrm{~J}=14.2 \mathrm{~Hz}, 1 \mathrm{H}), 1.68$ $(\mathrm{dd}, \mathrm{J}=4.5 \mathrm{~Hz}, \mathrm{~J}=14.3 \mathrm{~Hz}, 1 \mathrm{H}), 0.72(\mathrm{~s}, 9 \mathrm{H}) . \quad{ }^{13} \mathrm{C} \mathrm{NMR}\left(50.5 \mathrm{MHz}, \mathrm{CDCl}_{3}\right) \delta 150.3$, 
135.7, 129.2, 128.3, 128.2, 127.5, 91.0, 73.2, 49.1, 30.1, 26.1. Anal. Calcd. for $\mathrm{C}_{15} \mathrm{H}_{20} \mathrm{O}_{2}: \mathrm{C}_{\text {, }}$ 77.55; H, 8.68. Found: C, 77.63; H, 8.53.

\section{References}

1. For reviews see: (a) Noyori, R.; Suzuki, M. Angew. Chem. Int. Ed. 1984, 23, 847. (b) Perlmutter, P. In Conjugate Addition in Organic Synthesis, Pergamon: Oxford, 1992. (c) Collins, P. W.; Djuric, S. W. Chem. Rev. 1993, 93, 1533. (d) Nicolau, K. C.; Sorensen, E. J. In Classics in Total Synthesis, VCH: Weinheim, 1996. (e) Das, S.; Chandrasekhar, S.; Yadav, J. S.; Grée, R. Chem. Rev. 2007, 107, 3286.

2. Csákÿ, A. G.; Mba, M.; Plumet, J. J. Org. Chem. 2001, 66, 9026.

3. (a) Csákÿ, A. G.; Mba, M.; Plumet, J. Synlett 2003, 2092. (b) Csákÿ, A. G. ; Mba, M. ; Plumet, J. Tetrahedron Asymm. 2004, 15, 657. (c) Murcia, M. C.; de la Herrán, G.; Plumet, J.; Csákÿ, A. G. Synlett 2007, 1553.

4. de la Herrán, G.; Mba, M.; Murcia, M. C.; Plumet, J.; Csákÿ, A. G. Org. Lett. 2005, 7, 1669.

5. See for example: (a) Knöpfel, T.; Carreira, E. M. J. Am. Chem. Soc. 2003, 125, 6054. (b) Lerum, R. V.; Chisholm, J. D. Tetrahedron Lett. 2004, 45, 6591. (c) Chen, L.; Li, C. -J. Chem. Comm. 2004, 2362. (d) Kwak, Y. -S.; Corey, E. J. Org. Lett. 2004, 6, 3385. (e) Wu, R. T.; Chong, J. M. J. Am. Chem. Soc. 2005, 127, 3244. (f) Pellegrinet, S. C.; Goodman, J. M. J. Am. Chem. Soc. 2006, 128, 3116, and references cited therein.

6. For the addition of aluminium acetylides to protected 4-hydroxy-2-cyclopentenones, see: Yakura, T.; Tanaka, K.; Kitano, T.; Uenishi, J.; Ikeda, M. Tetrahedron 2000, 56, 7715.

7. Piancatelli, G.; D'Auria, M.; D'Onofrio, F. Synthesis 1994, 867 and therein cited references. See also: D'Auria, M. Heterocycles 2000, 52, 185.

8. (a) Salomon, M.; Jamison, M. L.; Mc.Cormick, M.; Liotta, D.; Cherry, D. A.; Mills, J. E.; Shah, R. D.; Rodgers, J. D.; Maryanoff, C. A. J. Am. Chem. Soc. 1988, 110, 3702. See also: (b) Beak, P.; Meyers, A. I. Acc. Chem. Res. 1986, 19, 356. (c) Hoveyda, A. H.; Evans, D. A.; Fu, G. C. Chem. Rev. 1993, 93, 1307.

9. For $\mathrm{OMgX}$-directed conjugate additions of organolithiums to $\alpha, \beta$-unsaturated nitriles see: (a) Fleming, F. F.; Wang, Q.; Steward, O. W. J. Org. Chem. 2001, 66, 2171. (b) Fleming, F. F.; Wang, Q.; Steward, O. W. J. Org. Chem. 2003, 68, 4235. (c) Fleming, F. F.; Zhang, Z.; Wang, Q.; Steward, O. W. Angew. Chem., Int. Ed. 2004, 43, 1126. (d) Fleming, F. F.; Zhang, Z.; Wei, G.; Steward, O. W. Org. Lett. 2005, 7, 447. (e) Fleming, F. F.; Zhang, Z.; Wei, G.; Steward, O. W. J. Org. Chem. 2006, 71, 1431. (f) Fleming, F. F. Vu, V. A.;

Shook, B. c.; Rahman, M.; Steward, O. W. J. Org. Chem. 2007, 72, 1432.

10. López, F.; Minnaard, A. J.; Feringa, B. L. Acc. Chem. Res. 2007, 40, 179. 